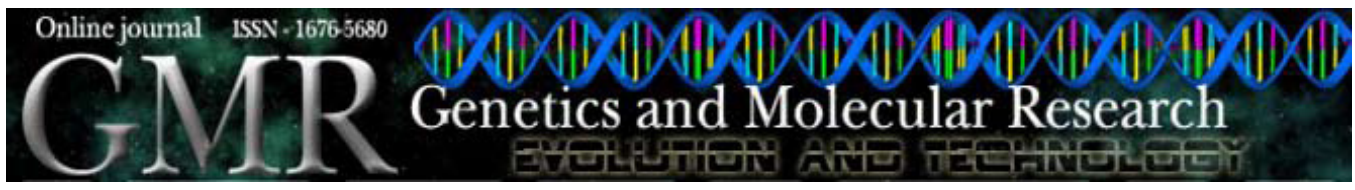

\title{
Aspergillus nidulans as a biological system to detect the genotoxic effects of mercury fumes on eukaryotes
}

G.D. Sousa ${ }^{1}$, T.D. Zucchi ${ }^{2}$, F.D. Zucchi ${ }^{3}$, R.G. Miller ${ }^{1}$, R.M.A. Anjos ${ }^{1}$, P. Poli ${ }^{4}$ and T.M.A.D. Zucchi ${ }^{3}$

${ }^{1}$ Departamento de Biologia Molecular, Universidade Católica de Brasília, Brasília, DF, Brasil

${ }^{2}$ Departamento de Entomologia, Fitopatologia and Zoologia Agrícola, Universidade de São Paulo, Piracicaba, SP, Brasil

${ }^{3}$ Departamento de Parasitologia, Instituto de Ciências Biomédicas and Centro de Pesquisas Biotecnológicas, Universidade de São Paulo, São Paulo, SP, Brasil ${ }^{4}$ Dipartimento di Genetica Antropologia Evoluzione, Università di Parma, Parma, Italy

Corresponding author: T.M.A.D. Zucchi

E-mail: tzucchi@uol.com.br.

Genet. Mol. Res. 8 (2): 404-413 (2009)

Received January 19, 2009

Accepted March 3, 2009

Published April 7, 2009

\begin{abstract}
Mercury (Hg) pollution is one of the most serious environmental problems. Due to public concern prompted by the symptoms displayed by people who consumed contaminated fish in Minamata, Japan in 1956, Hg pollution has since been kept under constant surveillance. However, despite considerable accumulation of knowledge on the noxious effects of ingested or inhaled $\mathrm{Hg}$, especially for humans, there is virtually nothing known about the genotoxic effects of $\mathrm{Hg}$. Because increased mitotic crossing over is assumed to be the first step leading to carcinogenesis, we used a sensitive short-term test (homozygotization index) to look for DNA alterations induced by $\mathrm{Hg}$ fumes. In one Aspergillus nidulans diploid strain (UT448//UT184), the effects of the Hg fumes appeared scattered all
\end{abstract}


over the DNA, causing 3.05 times more recombination frequencies than the mean for other strains. Another diploid ( $D p$ II-I//UT184) was little affected by Hg. This led us to hypothesize that a genetic factor present in the UT184 master strain genome, close to the nicB8 genetic marker, is responsible for this behavior. These findings corroborate our previous findings that the homozygotization index can be used as a bioassay for rapid and efficient assessment of ecotoxicological hazards.

Key words: Mercury genotoxicity; Genotoxicity detection;

Mitotic crossing-over; Homozygotization index; Ecotoxicological hazards

\section{INTRODUCTION}

In some Latin American areas, combinations of social and economic problems have pushed a lot of people towards gold panning. In the mining areas, mercury $(\mathrm{Hg})$ is used for amalgamation, a process that releases as much as $50 \%$ of the $\mathrm{Hg}$ used into the atmosphere. This turns Hg into an important environmental pollutant, mainly due to its high utilization by almost one million artisanal gold miners. In the past 20 years, Brazil has been ranked as first among South American countries in gold extraction, as the production ranges from 100 to 200 tons per year (Malm, 1998). Based on this account, it is estimated that 150 tons Hg contribute yearly to environmental pollution (Veiga, 1997).

Unlike most metals that function as a plant nutrient, $\mathrm{Hg}$ has no known physiological significance since it is not metabolized by most organisms (Israr et al., 2006). Inhalation of $\mathrm{Hg}$ vapor is the most significant way of contamination. In the lungs, $\mathrm{Hg}$ is oxidized forming complexes that are soluble in body fluids, whose ultimate effects are the inhibition of enzyme action (Jones et al., 1971) and restrictions on the metabolism of the central nervous system (Chang, 1979). Kidneys are the most affected organs under exposures of moderate duration, and the brain is the dominant receptor for long-term exposures (Suzuki, 1979). Besides such deleterious effects through evaporation by burning, $\mathrm{Hg}$ easily enters the water and food chain cycles. Even at low concentrations, Hg contamination may result in serious toxic effects in sensitive species along the food chain (Suszcynsky and Shann, 1995).

Even though this metal is well studied in terms of its bioavailability, bioaccumulation, biomagnifications, and cellular toxicity (Tran et al., 2007), there is a lack of information about its genotoxic effects as an inducer of mitotic recombination. On related matters, Pires and Zucchi (1994) devised a biological system known as the homozygotization index (HI) whose sensitivity in detecting mitotic recombination events is remarkable. Indeed, the HI test has been successfully applied to detect the genotoxic effects of several kinds of detrimental agents: physical (e.g., radiation; Stoll et al., 2008), chemical (e.g., medical products; Salvador et al., 2008) and biological (e.g., exogenous nucleic acids; Pires and Zucchi, 1998). This system invariably uses 2 or more Aspergillus nidulans diploid strains heterozygous for ten well-mapped genetic markers. One diploid (UT448//UT184) is well known for its perfectly stable and normal behavior during DNA recombination, methylation and repair mechanisms. The other ( $D p$ II-I//UT184) is also well-known genetically and shows the same heterozygous genetic markers of the first, except for the II-I transposed duplication shown in one of the haploid components, which affects DNA recombination, repair and methylation mechanisms. 
In this way, this biological system was adapted to evaluate the genotoxic effects of $\mathrm{Hg}$ fumes, which are usually associated with gold purification, a trivial method that exposes miners to the fumes produced. Additionally, interests were also centered on those $\mathrm{Hg}$ doses that cause structural DNA changes affecting its function in the mitotic recombination mechanism.

\section{MATERIAL AND METHODS}

\section{Strains}

Haploid strains of A. nidulans were obtained from Utrecht stocks (UT448 and UT184) from original Glasgow (UK) strains, and kept in the Zucchi's collection since 1978 (Instituto de Ciências Biomédicas da Universidade de São Paulo). The $D p$ II-I strain is a recombination/methylation mutant obtained after $N$-methyl- $N$ '-nitro- $N$-nitrosoguanidine (MNNG) treatment of the UT448 strain (Zucchi, 1990a; Castro-Prado and Zucchi, 1992; Castro-Prado et al., 1996); it bears a non-reciprocal duplication, transposed from chromosome II to chromosome I (paba-bio interval). The mutant loci as described according to Clutterbuck's suggestion (Clutterbuck, 1993) are given in Table 1.

\begin{tabular}{ll} 
Table 1. Genotype of Aspergillus nidulans strains. \\
\hline Strain & Genotype and linkage group \\
\hline UT184 & chaA1 (VIII), pyroA4 (IV), sB3 (VI), \\
& $n i c \mathrm{~B} 8$ (VII), riboB2 (VIII), galA1 (III), \\
& facA303 (V), lacA1 (VI), sulA1 (I), \\
& AcrA1 (II) \\
UT448 & $w \mathrm{~A} 2$ (II), riboA1, pabaA124, biA1 (I), \\
& AcrA1 (II), Dp II-I \\
& $w \mathrm{~A} 2$ (II), riboA1, pabaA124, biA1 (I) \\
AcrA1 (II) & $u v s \mathrm{~A} 1$ (II) \\
\hline
\end{tabular}

Requirements: riboA1 and riboB2 = riboflavin; $a b a \mathrm{~A} 124=p$-aminobenzoic acid; $b i \mathrm{~A} 1$ = biotin; pyroA4 = pyridoxine; $s \mathrm{~B} 3$ = sodium thiosulfate; nicB8 = nicotinamide. Carbon source: galA1 (III); facA303 (V) and lacA1 (VI): unable to utilize galactose, acetate and lactose as the sole carbon source, respectively. Conidium color: chaA1 = "chartreuse"; $w \mathrm{~A} 2$ = white. $A$. nidulans conidium color depends on pigments produced in the mature ascospores (for a review, see Dezotti and Zucchi (2001) and references therein). Resistance: AcrA1 = acriflavine; sulA1 = sulfanilamide. Sensitivity: uvsA1 = UV-light (Marin and Zucchi, 1991). Dp II-I = duplication of a segment of chromosome II transposed to chromosome I, inserted into paba-yA2 interval (Zucchi, 1990b; Castro-Prado and Zucchi, 1991a,b).

The UT448//UT184 and $D p$ II-I//UT184 diploid strains were prepared following Roper's (1952) methodology. The mutant alleles were allocated to their linkage groups by mitotic haploidization facilitated by treatment with $p$-fluorophenylalanine ( $p$ FA) (Forbes, 1959; Lhoas, 1961; Morpurgo, 1961).

\section{Media and culture condition}

The minimum (MM) and complete (CM) media follow the Van de Vate and Jansen (1978) methodology. CM was used to maintain stock cultures. The selective medium (SM) was MM supplemented according to the requirements of each strain $(1.00 \mathrm{mg} / \mathrm{mL}$ riboflavin, $0.70 \mathrm{mg} / \mathrm{mL}$ p-aminobenzoic acid, $0.02 \mathrm{mg} / \mathrm{mL}$ biotin, $0.50 \mathrm{mg} / \mathrm{mL}$ pyridoxine, $1 \mathrm{mg} / \mathrm{mL}$ nicotinamide, and 
$1.24 \mathrm{mg} / \mathrm{mL}$ sodium thiosulfate). SM lacking individually each requirement was used for determination of the haploid segregant genotypes. The carbon sources were also determined for each haploid segregant: SM lacking glucose and amended by lactose $(10 \mathrm{mg} / \mathrm{mL})$ or galactose $(10 \mathrm{mg} /$ $\mathrm{mL}$ ). Solid medium contained $1.5 \%$ agar. Stock cultures were grown at $37^{\circ} \mathrm{C}$ and kept at $4{ }^{\circ} \mathrm{C}$.

\section{Determination of $\mathrm{Hg}$ fume effects on viability of $\boldsymbol{A}$. nidulans conidia}

The Hg exposure period needed to produce $30 \%$ survivors was determined with conidia from each diploid in a fume hood. The amount of $\mathrm{Hg}$ used was estimated by the weight determination, before and after heating. After a 15-min exposure, $3 \mathrm{~g} \mathrm{Hg}$ was evaporated. This method was an attempt to reproduce a Brazilian miner's work conditions, where $\mathrm{Hg}$ is burned without any safety procedures. After treatments the plates were kept for $48 \mathrm{~h}$ at $37^{\circ} \mathrm{C}$ and conidium viability was evaluated.

The laboratories where this work was performed are biosafety certified by Conselho Técnico Nacional de Biossegurança (CTNBio; USP - CQB046-98 and UCB - CQB132/01). The $\mathrm{Hg}$ was evaporated in a metal column attached to a wood box and placed inside a fume hood (Figure 1). This experiment was performed after work hours and the operator was well-protected by individual protection equipment.

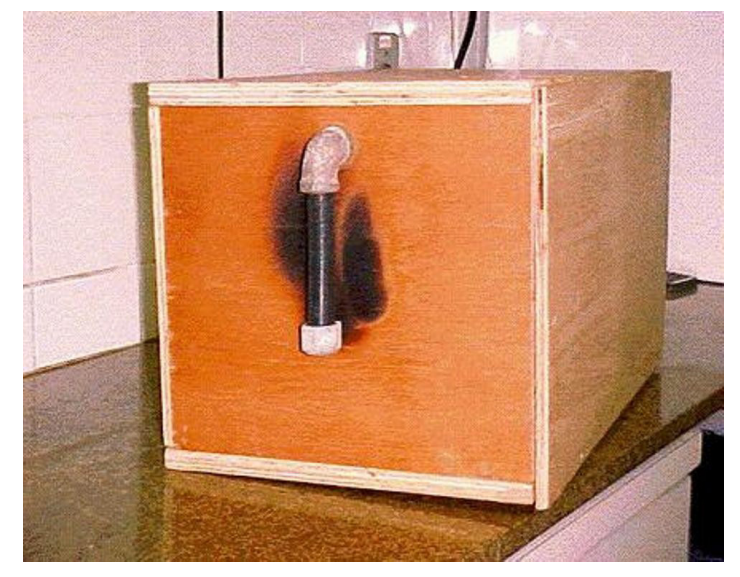

Figure 1. Experimental apparatus for the exposure of Aspergillus nidulans to Hg fumes.

\section{Evaluation of genotoxic effects of $\mathrm{Hg}$ fumes}

Microcolonies from both Hg-treated diploid strains were incubated for 5 days at $37^{\circ} \mathrm{C}$. Afterwards, conidium samples from the edge of each diploid colony were transferred to 20 plates containing $\mathrm{MM}$ and incubated for $8 \mathrm{~h}$ at $37^{\circ} \mathrm{C}$. After incubation, the plates containing microcolonies were subsequently exposed to $\mathrm{Hg}$ fumes for $15 \mathrm{~min}$, and the plates were then incubated at $37^{\circ} \mathrm{C}$ for $48 \mathrm{~h}$.

Ten individual $\mathrm{Hg}$ fume-treated diploid colonies, showing normal conidia and colony morphology, were selected and transferred to plates containing $\mathrm{CM}$ amended with the haploidizing agent $p \mathrm{FA}\left(\mathrm{CM}+p \mathrm{FA} 0.5 \mathrm{~mL} / 200 \mathrm{~mL}\right.$ of media). After 7 days of incubation at $37^{\circ} \mathrm{C}$, the haploid sectors (n) yielded were individually transferred to 25 defined positions of CM master plates $(5 \times 5$ pattern), and incubated for $48 \mathrm{~h}$. After this incubation period, the colonies were replicated on plates 
containing SM. The SM plates were observed after 24 and $48 \mathrm{~h}$ of incubation. Non-treated diploids were also haploidized and their haploid sectors were genotypically analyzed and used as reference control. The results were recorded, and the data obtained were organized in Latin squares format (data not shown) for mitotic crossing-over frequency determinations (Dezotti and Zucchi, 2001).

\section{Homozygotization index test}

The $\mathrm{HI}$ test herein adapted to evaluate the genotoxic potential of $\mathrm{Hg}$ fume to induce mitotic crossing-over in diploid cells of eukaryotic microorganisms had already been extensively used and frequently mentioned in the scientific literature (Zucchi et al., 2005; Salvador et al., 2008; Stoll et al., 2008).

This test is based on the induction of mitotic recombination in A. nidulans diploid strains, heterozygous for all genetic markers scattered all over their 8 chromosomes. These genetic markers included very known and well-mapped recessive mutations for a) nutritional requirements (e.g., deficiency in ribo, paba, bio, etc.), b) colony morphology (e.g., deteriorated, white, "chartreuse" or green conidia), resistance or sensitivity to antimycotic agents (e.g., acriflavine, sulfanilamide), inability to utilize determined carbon sources (e.g., galactose, acetate or lactose) (Zucchi, 1990b; Castro-Prado and Zucchi, 1991a, 1992). The induction of mitotic crossing-over may cause homozygotization and expression of recessive mutations.

After recombination events involving any genetic marker and centromeres, 4 kinds of diploid segregants may appear: $(+/ /+,+/ /-,-/ /+$, and $-/ /-)$. Since the induction treatment is performed in $\mathrm{MM}$, the recombinant diploids homozygous (-//-) for recessive nutritional markers cannot develop. Consequently, only the recombinant diploid conidia $(+/ /+,+/ /-$ and $-/ /+)$ will develop colonies. Those diploid colonies $(2 n=16)$ growing in MM, are then haploidized, in CM plus $p$ FA. Since the $p$ FA-treated diploids lose individual chromosomes randomly, by successive aneuploidy, until reaching the haploid ( $n=8$ chromosomes), the final result may reveal distorted allelic segregation rates higher than 2.0, depending on the number of induced recombinational events. In such a way, the HI obtained is a direct way to evaluate mitotic crossing-over frequency induced by genotoxic agents $(\mathrm{HI}=+/-)$ : the higher the $\mathrm{HI}$ values, the higher the mitotic recombination frequencies.

\section{Statistical analyses}

Using the Placas program (PLACAS, Copyright 2000 Bonato), mitotic analysis results were presented in Latin square table format. In these tables, data are presented to facilitate the observation of the interaction of genes with one another. These two-factor analyses provided a rapid check on abnormalities induced by the treatments and distortions on allelic segregation rates for each gene, and allowed statistical comparisons between the two allelic proportions (contingency table test, $\mathrm{P}<0.01$, with Yates correction).

\section{RESULTS}

\section{Conidium viability after $\mathrm{Hg}$ fumes exposure}

Conidia of the diploid strains were exposed to $\mathrm{Hg}$ fumes for different times. A 15-min exposure, equivalent to $3 \mathrm{~g}$ evaporated $\mathrm{Hg}$, induced $70 \%$ mortality, whereas lesser 
exposure times did not alter the survival rate (Table 2). In order to evaluate their survival performance, 400 microcolonies from each diploid were exposed to $\mathrm{Hg}$ fumes. In $\mathrm{MM}$, $8.0 \%$ of the UT448//UT184 and $12.5 \%$ of the $D p$ II-I//UT184 conidia developed microcolonies with morphological alterations, which deteriorated forming unstable colonies; these were not used in this study since our interests were in strains bearing normal DNA functions. Even so, those strains have had their stocks kept at $4^{\circ} \mathrm{C}$ for further molecular analyses. Only those demonstrating normal morphology, growth, conidiation, and cell divisions were selected for our present purposes where mitotic recombination frequencies after HI assay were evaluated for 9 genes simultaneously.

\begin{tabular}{|c|c|c|}
\hline $\begin{array}{l}\text { Exposure time } \\
\text { (s) }\end{array}$ & $\begin{array}{l}\text { Hg evaporated amount } \\
(\mathrm{g})\end{array}$ & $\begin{array}{c}\text { Cell survival } \\
(\%)\end{array}$ \\
\hline 30 & 0.32 & 100.0 \\
\hline 60 & 0.47 & 100.0 \\
\hline 900 & 3.00 & 30.0 \\
\hline
\end{tabular}

\section{Homozygotization index}

HI values for all genes analyzed were significantly different in the untreated diploids (controls) of the two strains UT448//UT184 and Dp II-I//UT184 (Table 3). The two diploid strains showed a different pattern. As explained before, the parental mutant $D p$ II-I strain, one of its haploid components, has an extra DNA segment, duplicated and transposed from chromosome II to the chromosome I. This mutation makes $D p$ II-I//UT448 diploid proficient only in recombinational repair mechanisms (Pires and Zucchi, 1994), and this character pattern was evidenced in many other works using the same diploid strains exposed to different genotoxic environmental agents (e.g., Salvador et al., 2008). Considerable distortions were observed when comparing the HI values between exposed and non-exposed colonies (Table 3).

Table 3. Homozygotization index of several markers of UT448//UT184 (A) and Dp II-I//UT184 (B) exposed to mercury fumes.

\begin{tabular}{|c|c|c|c|c|c|c|c|c|c|}
\hline & \multicolumn{9}{|c|}{ Linkage groups and markers } \\
\hline & I & I & I & II & IV & VI & VI & III & VII \\
\hline & ribo & paba & $b i$ & $W$ & pyro & lac & tio & gal & nic \\
\hline Treatment & & & & & $\mathbf{A}$ & & & & \\
\hline Control & $1.14^{\mathrm{a}}$ & $2.50^{\mathrm{a}}$ & $2.31^{\mathrm{a}}$ & $1.73^{\mathrm{a}}$ & $1.87^{\mathrm{a}}$ & $2.28^{\mathrm{a}}$ & $14.77^{\mathrm{a}}$ & $4.69^{\mathrm{a}}$ & $0.90^{\mathrm{a}}$ \\
\hline \multirow[t]{2}{*}{ Mercury vapor } & $22.00^{\mathrm{b}}$ & $17.40^{\mathrm{b}}$ & $5.57^{\mathrm{b}}$ & $5.81^{\mathrm{b}}$ & $19.44^{\mathrm{b}}$ & $7.76^{\mathrm{b}}$ & $25.29^{\mathrm{a}}$ & $4.26^{\mathrm{a}}$ & $0.02^{\mathrm{b}}$ \\
\hline & & & & & B & & & & \\
\hline Control & $9.28^{\mathrm{a}}$ & $10.57^{\mathrm{a}}$ & $5.01^{\mathrm{a}}$ & $5.17^{\mathrm{a}}$ & $13.47^{\mathrm{a}}$ & $9.07^{\mathrm{a}}$ & $14.97^{\mathrm{a}}$ & $6.12^{\mathrm{a}}$ & $2.11^{\mathrm{a}}$ \\
\hline Mercury vapor & $9.17^{\mathrm{a}}$ & $9.17^{\mathrm{a}}$ & $8.63^{\mathrm{a}}$ & $4.23^{\mathrm{a}}$ & $25.14^{\mathrm{a}}$ & $12.07^{\mathrm{a}}$ & $21.88^{\mathrm{a}}$ & $7.05^{\mathrm{a}}$ & $0.03^{\mathrm{b}}$ \\
\hline
\end{tabular}

Both heterozygous diploids, in minimum medium, were mercury vapor exposed (15 min), and the recombinant diploid segregants were then individually haploidized in complete medium $+p$-fluorophenylalanine. Their mitotic analyses allowed the determination of allelic segregation rates (+/-) for each genetic marker. Numbers followed by the same superscript letters have nonsignificant differences between treated and untreated cells $\left(\mathrm{P}<0.01 ; \chi^{2}\right.$ contingency table test). 
Table 3A presents individual HI data for all the genetic markers analyzed, individually, from the normal diploid strain (UT448//UT184), both treated and untreated. Statistical analyses showed that the untreated diploid had HI close to 2.0, as expected for single genes. Alternatively, when this diploid was treated with $\mathrm{Hg}$, a significant increase in $\mathrm{HI}$ values was detected for all genes examined.

In general, the highest HI values were displayed by the UT448//UT184 diploid strain that was $\mathrm{Hg}$ treated. For a fast detection of the $\mathrm{Hg}$ effects, the best ones among all the genetic makers were ribo, paba and pyro, which clearly showed the highest HI distortions.

Unusual behavior was demonstrated by the nicB8 individual genetic marker, which showed HI close to zero for both strains (Table 3A and B). Since homozygous recombinants for auxotrophic genetic markers were counter-selected in MM, the expected pattern is an increase in HI values. In this respect, the behavior of the gene marker for nicotinamide (nic), present in both UT448//UT184 and Dp II-I//UT184 strains, was unexpected. This suggests that close to the nic $\mathrm{B} 8$ marker there is an $\mathrm{Hg}$-resistant factor, inhibiting the recombination process in both strains. However, in UT448//UT184, this factor is unable to act on the other markers, suggesting that, in this strain, the factor was partially silenced. An appropriate meiotic analysis may precisely locate this factor on this chromosome.

Averaged HI values for both UT448//UT184 and Dp II-I//UT184 strains are then considered for the analysis of $\mathrm{Hg}$ recombinogenic effects (Figure 2).

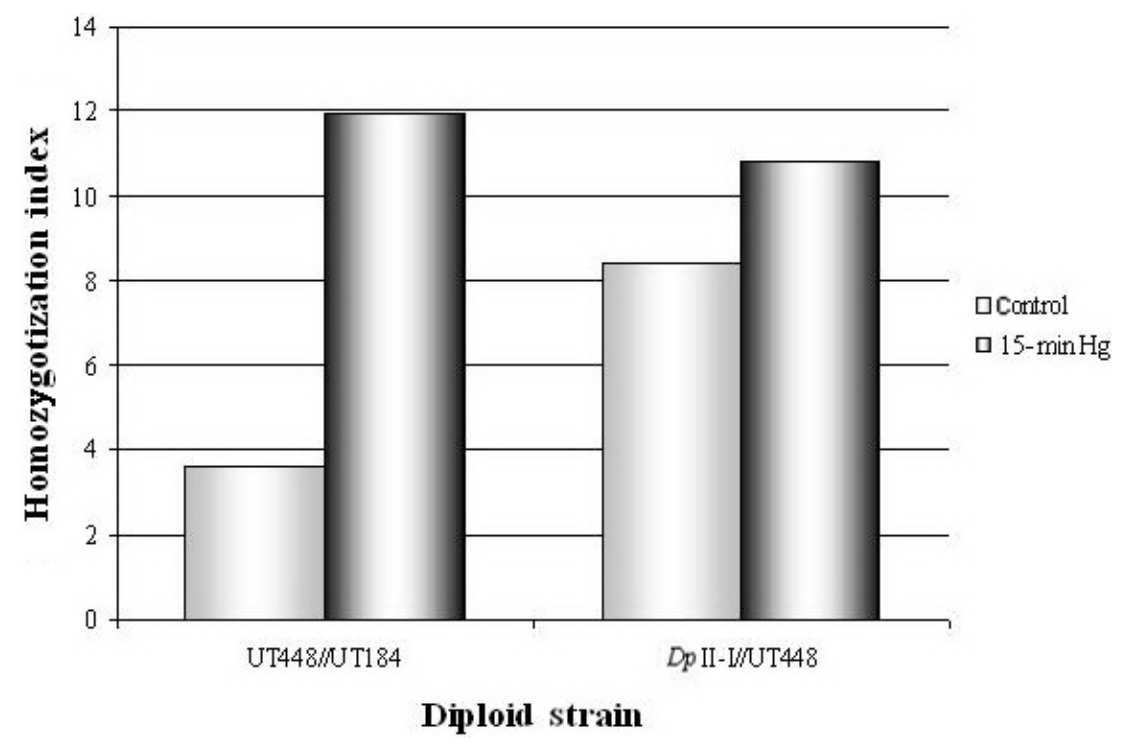

Figure 2. Homozygotization index (HI) averages of UT448//UT184 and Dp II-I//UT184 diploids. HI average values correspond to those presented in Table 3.

UT448//UT184 was very sensitive to Hg effects, suggesting that this strain is the most vulnerable to the recombinogenic effects of $\mathrm{Hg}$ fumes (Figure 2).

Based on its specific characteristics, Hg-exposed $D p$ II-I//UT448 was expected to show HI values significantly higher than those observed for the untreated diploid, as previous- 
ly reported for benzene fumes, UV and X-ray irradiation (Pires and Zucchi, 1994; Zucchi et al., 2005; Stoll et al., 2008), but contrarily, the results pointed towards a refractory behavior for this diploid, regarding $\mathrm{Hg}$ fumes. Specifically, this strain showed expected high values when exposed to $\mathrm{Hg}$ fumes (Figure 2). However, even when untreated, $D p$ II-I//UT184 displayed a typical behavior with a high level of mitotic recombination and high HI level. These and other previously reported findings (Pires and Zucchi, 1994; Zucchi et al., 2005; Stoll et al., 2008) suggest that eventual unrepaired DNA lesions were recombinogenic as well as DNA breaks resulting from the DNA replication mechanism (Pires and Zucchi, 1998).

\section{DISCUSSION}

The use of heterozygous diploid $A$. nidulans strain as a short-term test to detect genetic effects induced by environmental agents has proven to be efficient and able to evaluate induced genetic effects after several agent treatments even at sub-mutagenic doses. Indeed, this test can identify the environmental risks induced by single chemical agents (Zucchi et al., 2005; Miyamoto et al., 2007; Salvador et al., 2008; Stoll et al., 2008) as well as heterogeneous mixtures. In general, the use of biological systems focusing on genotoxicity detection of environmental contamination provides insight into the potential for increased mutation rates and alterations in the gene pool of various organisms (Lewis et al., 2006).

The mitotic recombination mechanism has important functions in eukaryotes and it is of rare occurrence. Detection of its alterations is important to evaluate the potential of environmental agents towards promoting recombinogenic and/or carcinogenic trends even at sub-mutagenic doses.

The use of microbiological systems for carcinogenicity and toxicity evaluation is quite common. Microbiological systems are faster, less expensive and produce valuable data. Besides, evaluating DNA damage is important for genetic toxicology, since chromosomal alterations are reported as one of the first step for the carcinogenesis event (Fenesh, 2000). Ames et al. (1973) described an important method that uses Salmonella thyphimuri$u m$ to evaluate mutagenesis. The use of $A$. nidulans arises as an efficient alternative, since it is an eukaryote with cellular and genetic mechanisms more complex than S. thyphimurium.

Of course, there are limitations to the use of $A$. nidulans as a mammal surrogate due to differences in the molecular environment and the complex genetic interactions. However, despite some limitations $A$. nidulans appears worth considering as a cell model to provide a rapid screening of the biological activities of environmental pollutants in the same way as in the Ames test.

Mercury in its elementary form is responsible for many environmental problems due to its accumulation in food chains and, consequently, in the human body. In this study, the importance of UT448//UT184 and Dp II-I//UT184 strains as model organisms to detect the genotoxic effects of $\mathrm{Hg}$ fumes was evaluated. Indeed, we only assessed the effects of a short acute exposure to Hg fumes in order to verify if the HI test with $A$. nidulans was able to detect the genotoxic capacity of this volatile environmental compound. Because the test was extremely sensitive under the experimental procedures, we can likely hypothesize that similar effects may occur under environmental conditions where chronic exposure to very low doses seems to be the usual tendency. The aim of the present study was not to evaluate dose-effect relationships, but only to simulate the working conditions to which miners in Brazil are usually submitted. Generally, $\mathrm{Hg}$ is burned directly with a 
blowtorch and the evaporated fumes are inhaled by the miners (Veiga, 1997). Other uses of this metal can represent additional risks to human health, since $\mathrm{Hg}$ can evaporate even under environmental temperatures as well.

Since our findings demonstrated alteration in the recombination frequency of the genetic markers tested, $\mathrm{Hg}$ cellular permeability has been characterized. Data from $D p$ II-I//UT184 indicated some refractoriness to this metal, but data from the UT448//UT184 assay showed high sensitivity of the strains to Hg fumes. The findings for both diploids, combined, demand special care to avoid the risks of hazardous occupational exposure. Furthermore, as far as we know, this is the first report where an A. nidulans diploid, proficient only in recombinational DNA repair mechanisms, showed a refractory behavior when treated with a genotoxic agent ( $\mathrm{Hg}$ fumes).

Also, a genetic factor close to the nic B8 gene may play a crucial role in both diploids. In the defective diploid ( $D p$ II-I//UT148), this factor could be responsible for the refractory pattern of $\mathrm{Hg}$ fumes. On the other hand, for the normal diploid (UT448// UT184), this factor displayed a low influence on protection against the noxious effect of $\mathrm{Hg}$ fumes. These peculiarities of gene regulation mechanisms are of particular importance because the actions of gene silencing or genomic protection may point to several aspects for the good functioning of the cellular machinery. Besides, the biological model applied here (the use of two A. nidulans diploid strains) was able to identify some peculiarities by simple Mendelian genetic approaches. Another important advantage is that the test is inexpensive as it does not involve modeling in animals.

As proved herein, bioassays focusing on mitotic recombination in A. nidulans were useful in clearly demonstrating the genotoxic effects of $\mathrm{Hg}$, supporting their applicability for other environmental pollutants. The versatility of this biological system has been verified by its use in several studies of mutagenesis and epigenetic alteration, covering a broad array of genetic events responsible for alterations in the functional mechanisms of DNA.

\section{ACKNOWLEDGMENTS}

We are grateful to Rosa Maria, Márcia Ferreira de Araújo, Paulo Marquêz, Dr. Vânia Gomes, USP Eukaryotic Genetic Laboratory students and UCB Biological Technology Laboratory students for their assistance and useful discussions. We are also indebted to Dr. Íris Ferrari (Faculdade de Medicina de Ribeirão Preto, USP and Universidade de Brasília) and Dr. Rui Caldas (Universidade Católica de Brasília) for helpful discussions. Research supported by CAPES, CNPq, FAPESP, and UCB.

\section{REFERENCES}

Ames BN, Durston WE, Yamasaki E and Lee FD (1973). Carcinogens are mutagens: a simple test system combining liver homogenates for activation and bacteria for detection. Proc. Natl. Acad. Sci. U. S. A. 70: 2281-2285.

Castro-Prado MAA and Zucchi TMAD (1991a). Stabilization of a duplicated segment DP (II-I) in an uvs mutant of Aspergillus nidulans through genetic mechanisms. Rev. Bras. Genet. 14: 239-248.

Castro-Prado MAA and Zucchi TMAD (1991b). Meiotic segregation of a recessive gene (wA2) included in a Dp(II,I) of Aspergillus nidulans. Rev. Bras. Genet. 14: 249-260.

Castro-Prado MAA and Zucchi TMAD (1992). Characterization of the Dp(II,I) in Aspergillus nidulans: presence of AcrA1 and its regulatory transcription sequence in the transposed segment. Rev. Bras. Genet. 15: 777-788. 
Castro-Prado MAA, Gebara JS, Querol CB, Zucchi OLAD, et al. (1996). Duplicate gene inactivation affects ascospore viability in Aspergillus nidulans. Braz. J. Genet. 19: 381-386.

Chang LW (1979). Pathological Effects of Mercury Poisoning. In: The Biogeochemistry of Mercury in the Environmental (Nrigau JO, ed.). Elsevier/North-Holland Biomedical Press, New York, 519-580.

Clutterbuck AJ (1993). Aspergilllus nidulans Maps, Genetic Loci $(\mathrm{n}=8)$. In: Genetic Maps (O’Brien SJ, ed.). Cold Spring Harbor, New York, 71-84.

Dezotti NO and Zucchi TMAD (2001). Identification of Aspergillus nidulans genes essential for the accumulation of sterigmatocystin. Fungal Genet. Biol. 34: 93-105.

Fenech M (2000). The in vitro micronucleus technique. Mutat. Res. 455: 81-95.

Forbes E (1959). Use of mitotic segregation for assigning genes to linkage groups in Aspergillus nidulans. Heredity 13: 67-80.

Israr M, Sahi S, Datta R and Sarkar D (2006). Bioaccumulation and physiological effects of mercury in Sesbania drummondii. Chemosphere 65: 591-598.

Jones JD, Rottschafer JM, Mark HB Jr, Paulsen KE, et al. (1971). Determination of traces of mercury in biological material by neutron activation. Mikrochim. Acta 3: 399-404.

Lewis MA, Daniels CB and Chancy CA (2006). Microbial genotoxicity as an environmental indicator for near-coastal sediment pore waters. Environ. Toxicol. 21: 193-204.

Lhoas P (1961). Mitotic haploidization by treatment of Aspergillus niger diploids with para-fluorophenylalanine. Nature 190: 744.

Malm O (1998). Gold mining as a source of mercury exposure in the Brazilian Amazon. Environ. Res. 77: 73-78.

Marin JM and Zucchi TMAD (1991). Genetic analysis of some factors affecting mitotic and meiotic behavior of a mutant of Aspergillus nidulans. Rev. Bras. Genet. 14: 9-20.

Miyamoto CT, Sant'Anna JR, Franco CC and Castro-Prado MA (2007). Genotoxicity (mitotic recombination) of the cancer chemotherapeutic agents cisplatin and cytosine arabinoside in Aspergillus nidulans. Food Chem. Toxicol. 45: 1091-1095.

Morpurgo G (1961). Somatic segregation induced by p-fluorophenylalanine. Aspergillus Newsletter 2: 10.

Pires LTA and Zucchi TMAD (1994). A new method to detect potential genotoxic agents using mitotic crossing-over in diploid strains of Aspergillus nidulans. Rev. Bras. Genet. 17: 371-376.

Pires LTA and Zucchi TMAD (1998). Ribonucleic acid treatment alters gene expression in diploid strains of Aspergillus nidulans. Cell. Mol. Biol. 44: 303-313.

Roper JA (1952). Production of heterozygous diploids in filamentous fungi. Experientia 8: 14-15.

Salvador JM, Zucchi TD, Schinor EC, Dias DA, et al. (2008). Genotoxic potentials of natural products detected by a shortterm test using diploid strains of Aspergillus nidulans. Open Mycol. J. 2: 48-54.

Stoll LB, Cremonesi FC, Pires LT, Zucchi TD, et al. (2008). Induction of mitotic crossing-over in diploid strains of Aspergillus nidulans using low-dose X-rays. Genet. Mol. Res. 7: 467-475.

Suszcynsky EM and Shann JR (1995). Phytotoxicity and accumulation of mercury in Tobacco subjected to different exposure routes. Environ. Toxicol. Chem. 14: 61-67.

Suzuki T (1979). Dose-effect and Dose-response Relationships of Mercury and its Derivatives. In: The Biogeochemistry of Mercury in the Environmental (Nrigau JO, ed.). Elsevier/North-Holland Biomedical Press, New York, 299-431.

Tran D, Moody AJ, Fisher AS, Foulkes ME, et al. (2007). Protective effects of selenium on mercury-induced DNA damage in mussel haemocytes. Aquat. Toxicol. 84: 11-18.

Van de Vate C and Jansen GJ (1978). Meiotic recombination in a duplication strain of Aspergillus nidulans. Genet. Res. 31: $29-52$.

Veiga MM (1997). Mercury in Artisanal Gold Mining in Latin America: Facts, Fantasies and Solutions. In: Introducing New Technology for Abatement of Global Mercury Pollution Deriving from Artisanal Gold Mining UNIDO - Expert Group Meeting, Vienna, July 1-3.

Zucchi TMAD (1990a). Isolation of putative recombination mutants of Aspergillus nidulans. Rev. Bras. Genet. 13: 409-424.

Zucchi TMAD (1990b). Location of the suppressor of methA17 mutation in the 30 mutant of Aspergillus nidulans. Rev. Bras. Genet. 13: 425-443.

Zucchi TD, Zucchi FD, Poli P, Melo IS, et al. (2005). A short-term test adapted to detect the genotoxic effects of environmental volatile pollutants (benzene fumes) using the filamentous fungus Aspergillus nidulans. J. Environ. Monit. 7: 598-602. 